\title{
Phenolic Acids from Parthenium hysterophorus: Evaluation of Bioconversion Potential as Free Radical Scavengers and Anticancer Agents
}

\author{
Richa Panwar ${ }^{1 *}$, Asvene Kumar Sharma1, Dharm Dutt², Vikas Pruthi1 \\ ${ }^{1}$ Department of Biotechnology, Indian Institute of Technology Roorkee, Roorkee, India \\ ${ }^{2}$ Department of Paper Technology, Indian Institute of Technology Roorkee, Roorkee, India \\ Email: panwarricha343@gmail.com
}

Received 15 December 2014; revised 29 December 2014; accepted 7 January 2015

Copyright (C) 2015 by authors and Scientific Research Publishing Inc.

This work is licensed under the Creative Commons Attribution International License (CC BY).

http://creativecommons.org/licenses/by/4.0/

(c) (i) Open Access

\begin{abstract}
Parthenium hysterophorus is a globally recognized invasive alien weed that prominently colonizes grazing areas and cultivated lands causing adverse effect on crop production. Major allelochemicals released from parthenium include sesqueterpene lactones and phenolic acids. Among these the presence of caffeic, vanillic and ferulic acids is of industrial significance as they possess potent free radical scavenging and anticancer activities. This study reports for the first time, high total phenolic acid content $(20.82 \pm 0.82 \mathrm{mg} \mathrm{GAE} / \mathrm{g}$ dry sample) in parthenium. The GC-MS analysis indicated the presence of ferulic, p-coumaric, vanillic and gallic acid as major phenolic components. Free radical scavenging activity of the phenolic acids extract gave an $\mathrm{EC}_{50}$ value $130.4 \mu \mathrm{g} / \mathrm{ml}$ when measured using DPPH assay. Anticancer activity of parthenium phenolic extract against A-498 $\left(\mathrm{IC}_{50} 0.5237 \mu \mathrm{g} / \mathrm{ml}\right.$ ) and MDA-MB231 ( $\mathrm{IC}_{50}$ and $0.2685 \mu \mathrm{g} / \mathrm{ml}$ ) cancerous cell lines indicated its potential to be used as anticancer agent.
\end{abstract}

\section{Keywords}

Parthenium hysterophorus, Phenolic Acids, GC-MS, Antioxidant, Bioconversion

\section{Introduction}

Parthenium hysterophorus (Asteraceae) is a widely distributed invasive agricultural weed causing environmen-

*Corresponding author.

How to cite this paper: Panwar, R., Sharma, A.K., Dutt, D. and Pruthi, V. (2015) Phenolic Acids from Parthenium hysterophorus: Evaluation of Bioconversion Potential as Free Radical Scavengers and Anticancer Agents. Advances in Bioscience and Biotechnology, 6, 11-17. http://dx.doi.org/10.4236/abb.2015.61002 
tal threats [1]. The major allelochemicals present in parthenium are sesquiterpene lactones mainly parthenin and phenolics group that includes caffeic, vanillic, ferulic, chlorogenic and anisic acids which are responsible for affecting many plant species [2]. As a result of their higher antioxidant potential [3], polyphenolic compounds are gaining attention across the scientific community among various medicinally important products isolated from plants. They are reported to impart equivalent health benefits as are obtained from consuming rich diet comprising of fruits and vegetables [4]. This diversified group of secondary metabolites, derived from the shikimate pathway and phenylpropanoid metabolism, possesses one or more hydroxy substituted aromatic rings [5]. These compounds are classified into simple phenols, phenolic acids, coumarins, tannins and flavonoids. Besides antioxidant potential, studies also suggest anticancer effects of phenolic acids on different types of cancerous cell lines [6]. Owing to the broad spectrum of medical applicability of phenolics, it is necessary to obtain them from inexpensive resources. In this investigation, phenolic acids extract from an agricultural weed parthenium was tested for its bioconversion as potent antioxidant and anticancer agent.

\section{Materials and Methods}

\subsection{Materials}

The raw material (parthenium leaves) used in the study was collected from the agricultural fields surrounding IIT Roorkee campus and specimen of the same was identified and authenticated as Parthenium hysterophorus by Forest Research Institute, Dehradun, India. Standard ferulic acid, p-coumaric acid, vanillic acid, gallic acid, 2-methoxy-4-vinylphenol and DPPH were purchased from Sigma-Aldrich Fine Chemicals (St. Louis, MO). Folin-Ciocalteu reagent, ethyl acetate, sodium hydroxide, sodium dihydrogen phosphate, hydrochloric acid, sodium hydrogen sulfite, acetonitrile HPLC grade, acetic acid HPLC grade, ethanol and Silica gel $60 \mathrm{~F}_{254}$ plates were purchased from Merck (Darmstadt, Germany). Cell lines viz. A-498 (Human Kidney Carcinoma), MDAMB231 (Human Mammary Gland Carcinoma) and HaCaT (Human Keratinocyte) were procured from NCCS Pune and maintained in MEM (minimum essential medium) containing 10\% FBS (Fetal Bovine Serum) and in DMEM (Dulbecco's Modified Eagle Medium) with 10\% FBS. All solvents and reagents used were of highest purity grade.

\subsection{Extraction of Phenolic Acids}

Phenolic acids were extracted from parthenium leaves which are reported to contain higher amount of phenolic content in them when compared to roots [7]. Modified alkaline hydrolysis method, specific for phenolic acids extraction was used for the study [8]. Parthenium leaves were dried in a universal oven at $45^{\circ} \mathrm{C}$ overnight and grounded to powder. Dried leaves powder (10 g) was saponified with $300 \mathrm{~mL} \mathrm{NaOH} \mathrm{(2} \mathrm{M)} \mathrm{on} \mathrm{a} \mathrm{rotary} \mathrm{shaker} \mathrm{at}$ $180 \mathrm{rpm}$ for $24 \mathrm{~h}$ at room temperature. To prevent oxidation of phenolics $0.0001 \mathrm{~g}$ of sodium hydrogen sulfite was added to the solution. The alkaline hydrolysate so obtained was centrifuged and the $\mathrm{pH}$ of supernatant adjusted to 2, with dilute hydrochloric acid (2 M). Precipitated phenolic acids were then extracted thrice using ethyl acetate. Organic fraction was collected, concentrated by rotary vacuum evaporator (Buchi Rotavapor R-210, Switzerland) and finally dissolved in $2 \mathrm{ml}$ acetonitrile:water (20:80) mixture. The extract was then filtered through $0.45 \mu \mathrm{m}$ nylon filter for further analysis. The presence of phenolic acids in the alkaline extract was confirmed by qualitative TLC. Extracted sample along with standards (ferulic acid, caffeic acid, p-coumaric acid, vanillic acid and gallic acid) were chromatographed on precoated $10 \mathrm{~cm} \times 20 \mathrm{~cm}(0.25 \mathrm{~mm}$ thick) silica gel 60 $\mathrm{F}_{254}$ plates using chloroform:methanol:formic acid (85:15:1) as mobile phase in a pre-saturated chromatography chamber. The plates were then air dried at room temperature, sprayed with $1 \%$ ferric chloride and the distinctive colors for each phenolic acid were recorded [9].

\subsection{Estimation of Phenolic Concentration}

The concentration of phenolics in the extracted phenolic acid sample was measured by modified Folin-Ciocalteu method using gallic acid standard curve [10]. Absorbance of the standards and the tests were measured after 30 min dark incubation at $650 \mathrm{~nm}$ using spectrophotometer (Agilent Cary 60). Results were expressed as milligrams gallic acid equivalents (GAE) per gram dry weight of sample. All tests were made in triplicate.

\subsection{Chemical Analysis by GC-MS}

Phenolic acids extract was subjected to chemical analysis by GC-MS, following the modified protocol [11]. An 
Agilent Model 7890A gas chromatograph, equipped with a split/splitless injection port, having interface with an Agilent 5975C inert mass-selective detector, was used. Fused silica (DB-5MS) capillary column (J\&W Scientific, Folsom, CA, USA) with the dimensions $30 \mathrm{~m} \times 0.25 \mathrm{~mm}$ i.d., $0.25 \mathrm{~mm}$ was used. Ultra high purity helium acted as carrier gas, set at a flow of $1.2 \mathrm{~mL} / \mathrm{min}$ and column head pressure at $26.00 \mathrm{psi}$. The temperature of the injector was maintained at $320^{\circ} \mathrm{C}$ and the injected sample volume was $2 \mu \mathrm{L}$ with 1:50 split ratio. Interface temperature was held at $280^{\circ} \mathrm{C}$. The column temperature program was set with oven equilibration time of $2 \mathrm{~min}$; initial temperature $150^{\circ} \mathrm{C}$ for $3 \mathrm{~min}$, raised to $292^{\circ} \mathrm{C}$ at a rate of $5^{\circ} \mathrm{C} / \mathrm{min}$ and then to $320^{\circ} \mathrm{C}$ at a rate of $30^{\circ} \mathrm{C} / \mathrm{min}$ with a final isotherm of $4 \mathrm{~min}$. The mass spectrometer was calibrated with perfluorotributylamine at electron impact ionization energy of $70 \mathrm{eV}$. GC-MS analysis of extracts was carried out in scan mode. Identification of the resulting peaks was done by comparing the retention times with those of commercial standards (ferulic, p-coumaric, caffeic, anisic, gallic, vanillic acid etc.) and the spectral data obtained from NIST libraries.

\subsection{Free Radical Scavenging Activity}

DPPH (2, 2-diphenyl-1-picryl-hydazyl) assay was used to determine radical scavenging activity of extracted sample using earlier reported protocol with necessary modifications [12]. Stock solution of DPPH was prepared by dissolving $16 \mathrm{mg}$ DPPH in $100 \mathrm{~mL}$ of ethanol and $100 \mathrm{mLof}$ distilled water. Different concentration (20, 40, 60,80 and $100 \mu \mathrm{g} / \mathrm{ml}$ ) of extract was prepared and from each of them $200 \mu \mathrm{L}$ of extract was added to $0.8 \mathrm{ml}$ of DPPH stock solution. Each mixture was shaken and left for $30 \mathrm{~min}$ at room temperature, and the absorbance of the resulting solution was measured at $517 \mathrm{~nm}$ with spectrophotometer (Agilent Cary 60). Radical scavenging activity was calculated according to the following equation:

$$
\text { Free radical scavenging activity }(\%)=\text { Ac }- \text { As/Ac } \times 100
$$

where Ac $=$ control absorbance; As = sample absorbance.

\subsection{In-Vitro Cytotoxicity Analysis}

The cytotoxicity of the phenolic acid extract was tested on A-498, MDA-MB231 cancerous cells and noncancerous cell line HaCaT used as a control. Monolayer cell culture of A-498, MDA-MB231 and HaCaT was trypsinized and the cell count was adjusted to $0.5-1.0 \times 10^{5}$ cells $/ \mathrm{ml}$ using $10 \%$ FBS medium [13]. From the diluted cell suspension, $0.1 \mathrm{ml}$ (approximately 10,000 cells) was then added to each well of microtiter plate. After 24 hours, when a partial monolayer was formed, the supernatant was flicked off, washed with PBS and $200 \mu \mathrm{l}$ of fresh medium respective to each cell line was added. Following this, $50 \mu \mathrm{l}$ of parthenium phenolic extract was added to the first well of each test column and serially diluted ( $1 / 40$ folds). The plates were then incubated at $37^{\circ} \mathrm{C}$ for 72 hours in $5 \% \mathrm{CO}_{2}$ incubator, and examined microscopically. Subsequently, the MTT solution $(20 \mu \mathrm{L}$ of $5 \mathrm{mg} / \mathrm{mL}$ stock) was added to each well containing sample, and incubated at $37^{\circ} \mathrm{C}$ for $6 \mathrm{~h}$. The solution in the wells was then removed carefully and $200 \mu \mathrm{L}$ of DMSO was added to dissolve the MTT formazan crystals. Lastly, $100 \mu \mathrm{L}$ of the dissolved formazan solution of each test sample was transferred to individual wells of 96well plate to determine the absorbance at $570 \mathrm{~nm}\left(A_{570 \mathrm{~nm}}\right)$ using microplate reader (Fluostar optima, BMG labtech, Germany). Concentration at which $50 \%$ cells are viable ( $\left.\mathrm{IC}_{50}\right)$ was calculated in terms of cell viability (\%) as stated below, which was directly proportional to metabolically active cell number.

$$
\text { Cell viability }(\%)=\mathrm{OD}_{570 \mathrm{~nm}}(\text { test samples }) / \mathrm{OD}_{570 \mathrm{~nm}}(\text { control }) \times 100
$$

\subsection{Statistical Analysis}

All analyses were done in triplicate. Results were expressed as means \pm standard deviations of each independent experiment and one-way analysis of variance (ANOVA) was performed to evaluate the significant differences between sample means, with significant level at $\mathrm{p}<0.05$. Graphpad Prism biostatics software version 6.0 was used for calculation of $\mathrm{IC}_{50}$ and $\mathrm{EC}_{50}$ values of phenolic acid extract for cell lines and $\mathrm{DPPH}$ radical scavenging.

\section{Results and Discussion}

\subsection{Phenolic Concentration}

Total phenolics concentration in parthenium extract was calculated to be $20.82 \pm 0.82 \mathrm{mg} / \mathrm{g}$ sample dry weight 
using gallic acid as a standard. This amount, estimated by Folin-Ciocalteu reagent was found to be much higher as compared to $275 \mathrm{mg} / 100 \mathrm{~g}$ dry weight reported earlier [7].

\subsection{GC-MS Analysis}

Prior to phenolic acid analysis by GC-MS qualitative TLC of crude parthenium phenolic extract along with standard was performed on pre coated silica gel $60 \mathrm{~F}_{254}$ plates using chloroform:methanol:formic acid (85:15:1) as mobile phase. Data obtained showed the presence of ferulic, vanillic, gallic and p-coumaric acid in the extract which was then subjected to GC-MS analysis. Total Ion Chromatogram (TIC) of phenolic acids that are identified in parthenium extract is represented in Figure 1. The major identified compounds are assigned peak number 1, 2, 3 and 4 in TIC with their relative mass spectra analysis (Figure 1). Peak 1 corresponds to vanillic acid with retention time of 11.5 minutes, covering $22.1 \%$ area of TIC. Similarly peak 2, 3 and 4 represents p-coumaric, ferulic and gallic acid with retention times of 16.2, 18.2, 19.5 minutes, covering an area of $20.61 \%, 31.22 \%$ and $6.87 \%$ respectively. Ferulic acid was recorded to be the most abundant of all the identified compounds, followed by vanillic, p-coumaric and gallic acid. Ferulic and p-coumaric acids are the prominent members of subgroup hydroxycinnamic acids of phenols with a three-carbon side chain whereas vanillic acid and gallic acids are diand trihydroxybenzoic acids respectively. Another phenolic compound 2-methoxy-4-vinylphenol was detected in trace amounts.

\subsection{Free Radical Scavenging Activity}

DPPH is a nitrogen centered free radical which gives strong absorption maximum at $517 \mathrm{~nm}$. The change in color of solution from yellow to purple occurs as the singlet electron in DPPH free radical becomes paired with hydrogen, from free radical scavenging antioxidant to form the reduced DPPH-H. Free radical scavenging effect (antioxidant potential) of phenolic acids extract at different concentration (20, 40, 80, 100 and $200 \mu \mathrm{g} / \mathrm{ml}$ ) was plotted against percentage inhibition (6.47\%, 10.92\%, 31.89\%, 48.97\% and 73.59\% respectively) using ascorbic acid as a standard which showed a dose dependent radical scavenging activity. $\mathrm{EC}_{50}$ values of standard and sample were recorded to be $130.4 \pm 1.2 \mu \mathrm{g} / \mathrm{ml}$ and $9.7 \pm 0.98 \mu \mathrm{g} / \mathrm{ml}$ respectively. GC-MS analysis of phenolic acids extract clearly indicated that the major portion of extract comprises of phenolic acids viz. ferulic, p-coumaric, vanillic and gallic acid, which have an ability to scavenge free radicals and donate hydrogen atoms or electron. Ferulic acid in particular, is reported to possess high antioxidant activity, making it a potent therapeutic agent [14]. Hence, the high antioxidant activity shown by the extract could be attributed to ferulic acid which was detected to be major phenolic acid component in it.

\subsection{In-Vitro Cytotoxicity}

Cytotoxic activity of phenolic acid extract of parthenium at varying concentrations against A-498 and MDAMB231 cancerous cell lines is shown in Figure 2. Significant inhibition of more than 50\% was observed at $0.834 \mu \mathrm{g} / \mathrm{ml}$ of extract concentration for both A-498 and MDA-MB231 whereas a negligible effect was shown by non cancerous HaCaT cell lines (control) at this concentration. Cancerous cells A-498 and MDA-MB231 had IC $_{50}$ values of $0.5237 \mu \mathrm{g} / \mathrm{ml}$ and $0.2685 \mu \mathrm{g} / \mathrm{ml}$ respectively. The IC $\mathrm{C}_{50}$ value for HaCaT cells was calculated to be $69.91 \mu \mathrm{g} / \mathrm{ml}$, from which it could be inferred that these cells are only slightly affected with phenolic acid extract of parthenium with maximum inhibition $29.6 \%$ observed at highest concentration $(20.84 \mu \mathrm{g} / \mathrm{ml})$. These results indicated that the extract possesses good cytotoxic activity against the cancerous cells A-498 (Human Kidney Carcinoma) and MDA-MB231 (Human Mammary Gland Carcinoma) as shown in Figure 3. Among naturally occurring phenolic acids, ferulic acid is extensively studied and reported to be a strong inhibitor of various cell lines including human breast cancer cell lines, neuronal cell culture system and human cervical carcinoma cells [15]-[17]. The strong cytotoxicity of the studied phenolic acid extract against cancerous cell could be attributed to the presence of ferulic acid since it is detected in highest amount in the extract. The inhibitory effect of naturally occurring polyphenols against carcinogenesis and tumor growth is reported occur through different mechanism such as modification of the redox status of cells or interference with basic cellular functions such as cell cycle process and its regulation, apoptosis, inflammation, invasion and metastasis [16]. The analysis, carried out to study the effect of parthenium phenolic acid extract reported the inhibition of cancerous cell proliferation. However, to get more in-depth knowledge on the physiological changes to ascertain, whether the phenolic extract of parthenium is causing damage at molecular level or at protein level is required. 

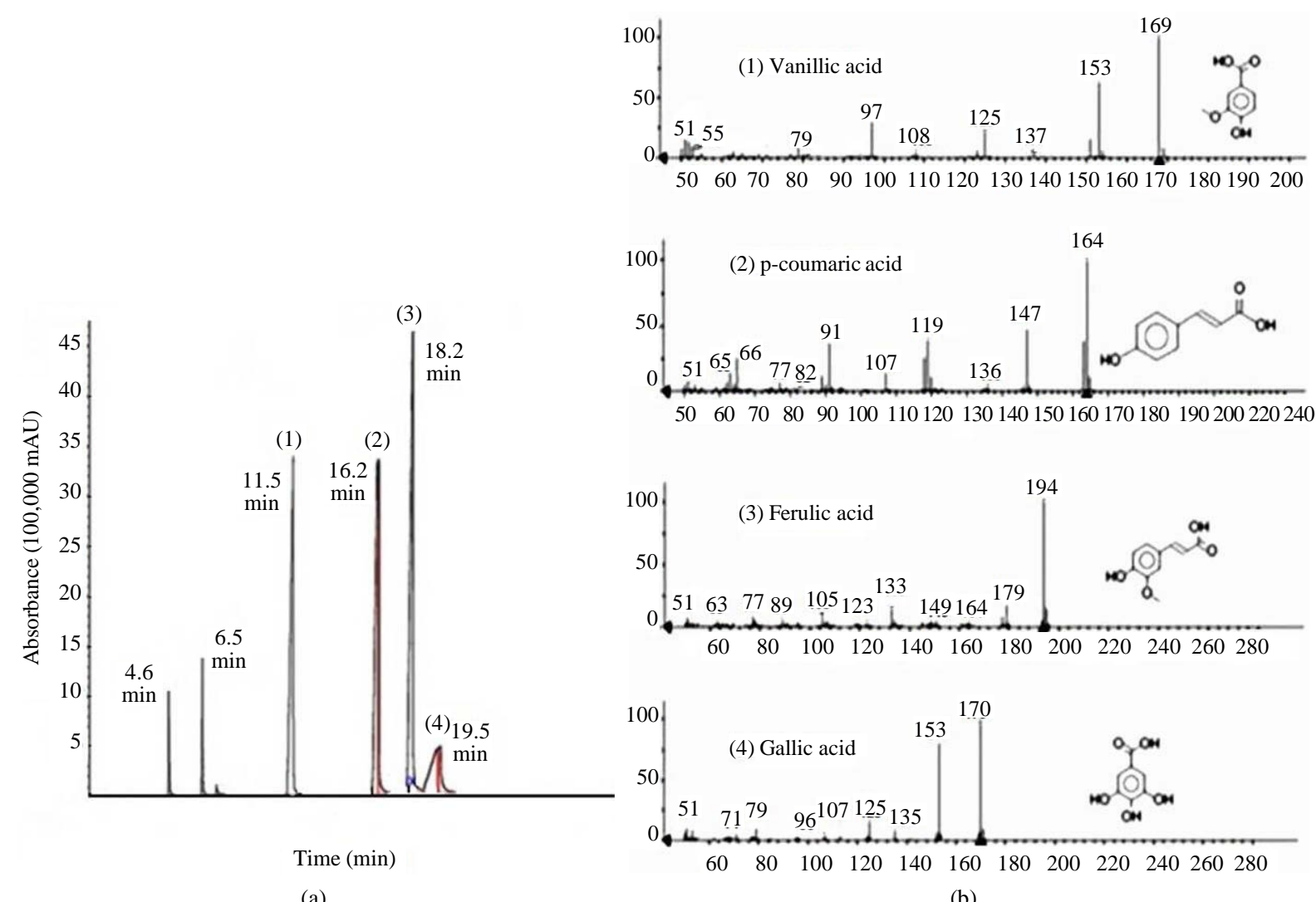

(a)

(b)

Figure 1. TIC chromatogram of phenolic acids from parthenium extract and MS spectrograms of major TIC peaks. Panel A: Major compounds identified by GC-MS are indicated with peak number 1, 2, 3 and 4. Panel B: MS spectrogram of compounds corresponding to each peak with structure and characteristic ions (m/z ratio). 1, 2, 3, 4 depicts vanillic acid, p-coumaric acid, ferulic and gallic acid respectively.

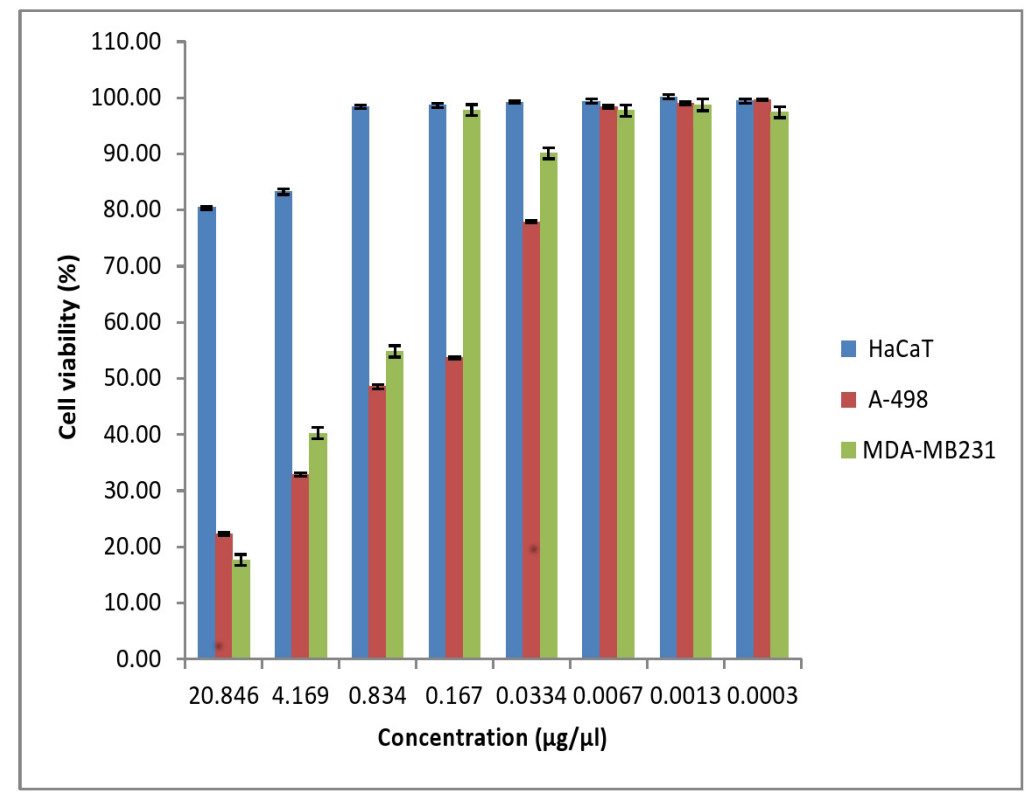

Figure 2. Effect of parthenium phenolic acids extract on cell proliferation: Cytotoxic effect of different concentrations of parthenium phenolic acids extract on the percentage viability of HaCaT, A-498 and MDA-MB231 cell lines. Values are based on triplicate tests; each column represents the mean \pm SD $(n=3)$. 


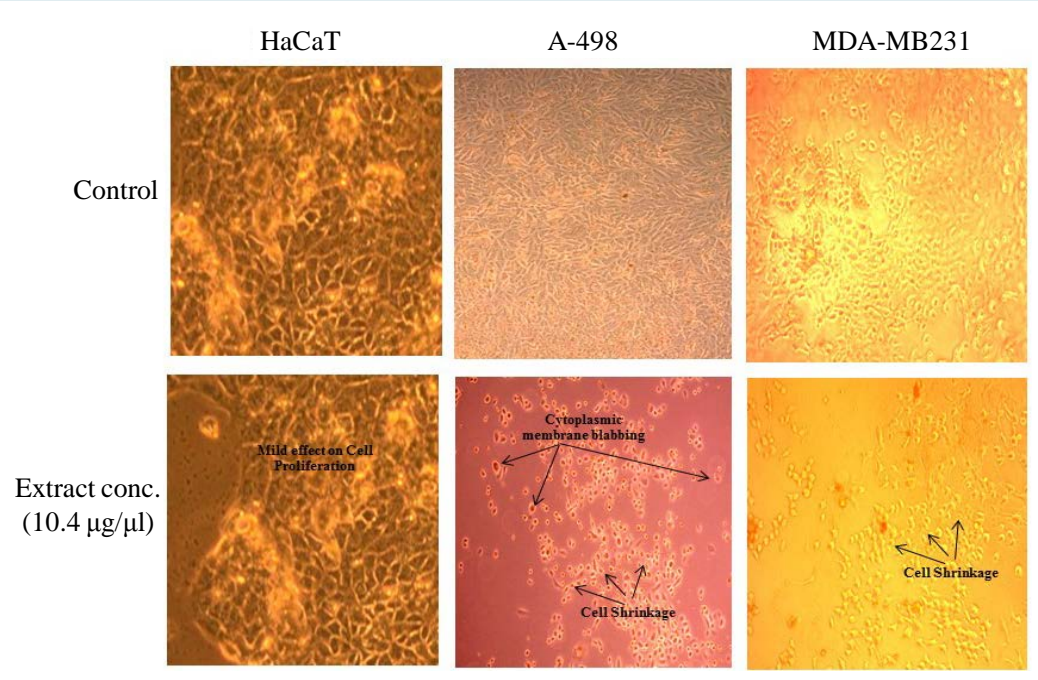

Figure 3. Phase contrast analysis of HaCaT, A-498 and MDA-MB231. Cells grown for $72 \mathrm{~h}$ in the presence of parthenium phenolic acid extracts $(10.4 \mu \mathrm{g} / \mu \mathrm{l})$ exhibiting cell shrinkage and cytoplasmic membrane blabbing. Control cells showed very small morphological changes at the same extract concentration. Microscope magnification (10×).

\section{Conclusion}

This study provides the first report on the high content of total phenols in parthenium extract which possess significant levels of natural antioxidants ferulic, p-coumaric and vanillic acid. These identified phenolic acids were found to exhibit strong antioxidant and anticancerous activities. The results obtained may serve as a scientific foundation for further isolation and purification of therapeutically important phenolic acids from inexpensive sources such as parthenium their bioconversion for the development of cost effective drugs against different types of deadly cancers.

\section{Acknowledgements}

Authors are thankful to Indian Institute of Technology Roorkee, U.K., India, for providing the infrastructural facilities to carry out the research work and financial support to RP under MHRD assistance (MHRD-02-23-200429).

\section{References}

[1] Ghosh, S., Haldar, S., Ganguly, A. and Chatterjee P.K. (2013) Review on Parthenium Hysterphorus as a Potential Energy Source. Renewable and Sustainable Energy Reviews, 20, 420-429. http://dx.doi.org/10.1016/j.rser.2012.12.011

[2] Swaminathan, C., Vinaya, R.R.S. and Sureshi, KK. (1990) Allelopathic Effects of Parthenium hyterophorus L. on Germination and Seedling Growth of a Few Multipurpose Tress and Arable Crops. International Tree Crops Journal, 6, 143-150. http://dx.doi.org/10.1080/01435698.1990.9752880

[3] Durre, S. and Muhammad, A.R. (2012) Antioxidant Potential of Phenolic Extracts of Mimusops elengi. Asian Pacific Journal of Tropical Biomedicine, 2, 547-550. http://dx.doi.org/10.1016/S2221-1691(12)60094-X

[4] Parr, A.J. and Bolwell, G.P. (2000) Phenols in the Plant and in Man. The Potential for Possible Nutritional Enhancement of the Diet by Modifying the Phenols Content or Profile. Journal of the Science of Food and Agriculture, 80, 985-1012. http://dx.doi.org/10.1002/(SICI)1097-0010(20000515)80:7<985::AID-JSFA572>3.0.CO;2-7

[5] Ryan, D., Robards, K., Prenzler, P. and Antolovich, M. (1999) Applications of Mass Spectrometry to Plant Phenols. TRAC-Trends in Analytical Chemistry, 18, 362-372. http://dx.doi.org/10.1016/S0165-9936(98)00118-6

[6] Luana, D.R., Mariana, C.M. and Anderson J.T. (2012) Anticancer Properties of hydroxycinnamic Acids-A Review. Cancer and Clinical Oncology, 1.

[7] Chandrakala, M.V., Prakash, D., Patil, R.R., Sukumar, J., Maribashetty, V.G., Gururaj, C.S., Shivakumar, C. and Sekharappa, B.M. (2012) Investigation on the Application of Parthenium hysterophorus Extracts as Feed Additives for Young Larvae of Silkworm. Bombyx mori L. Agricultural Science Research Journals, 2, 449-452.

[8] Tilay, A., Bule, M., Kishenkumar, J. and Annapure, U. (2008) Preparation of Ferulic Acid from Agricultural Wastes: 
Its Improved Extraction and Purification. Journal of Agricultural and Food Chemistry, 56, 7644-7648. http://dx.doi.org/10.1021/jf801536t

[9] Leonard, V.M., Tungamirai, M. and John, M.B. (2006) Determination of Ferulic Acid and Related Compounds by Thin Layer Chromatography. African Journal of Biotechnology, 5, 1271-1273.

[10] Kumbhare, M.R., Guleha V. and Sivakumar T. (2012) Estimation of Total Phenolic Content, Cytotoxicity and In-Vitro Antioxidant Activity of Stem Bark of Moringa oleifera. Asian Pacific Journal of Tropical Disease, 144-150. http://dx.doi.org/10.1016/S2222-1808(12)60033-4

[11] Lucio, M. and Roberto, P. (2008) Determination of Phenolic Compounds in Wines by Novel Matrix Solid-Phase Dispersion Extraction and Gas Chromatography/Mass Spectrometry. Journal of Chromatography A, 1185, 23-30. http://dx.doi.org/10.1016/j.chroma.2008.01.039

[12] Lee, J.S., Kim, G.H. and Lee, H.G. (2010) Characteristics and Antioxidant Activity of Elsholtzia splendens ExtractLoaded Nanoparticles. Journal of Agricultural and Food Chemistry, 58, 3316-3321. http://dx.doi.org/10.1021/jf904091d

[13] Ammar, S., Michael, H., Pirkko, H. and Kalevi, P. (2002) Inhibition of Cancer Cell Growth by Crude Extract and the Phenolics of Terminalia chebula Retz Fruit. Journal of Ethnopharmacology, 81, 327-336. http://dx.doi.org/10.1016/S0378-8741(02)00099-5

[14] Marimuthu, S., Adluri, R.S. and Venugopal, P.M. (2007) Ferulic Acid: Therapeutic Potential through Its Antioxidant Property. Journal of Clinical Biochemistry and Nutrition, 40, 92-100. http://dx.doi.org/10.3164/jcbn.40.92

[15] Jaroslaw, K., Marina, A., Antonia, S. and Butterfield, D.A. (2002) Ferulic Acid Antioxidant Protection against Hydroxyl and Peroxyl Radical Oxidation in Synaptosomal and Neuronal Cell Culture Systems in Vitro: Structure-Activity Studies. Journal of Nutritional Biochemistry, 13, 273-281. http://dx.doi.org/10.1016/S0955-2863(01)00215-7

[16] Kampa, M., Nifli, A.P., Notas, G. and Castanas, E. (2007) Polyphenols and Cancer Cell Growth. Reviews of Physiology, Biochemistry \& Pharmacology, 159, 79-113.

[17] Subburayan, K., Govindhasamy, K., Nagarajan, R.P. and Rajendran, M. (2011) Radiosensitizing Effect of Ferulic Acid on Human Cervical Carcinoma Cells in Vitro. Toxicology in Vitro, 25, 1366-1375.

http://dx.doi.org/10.1016/j.tiv.2011.05.007 
Scientific Research Publishing (SCIRP) is one of the largest Open Access journal publishers. It is currently publishing more than 200 open access, online, peer-reviewed journals covering a wide range of academic disciplines. SCIRP serves the worldwide academic communities and contributes to the progress and application of science with its publication.

Other selected journals from SCIRP are listed as below. Submit your manuscript to us via either submit@scirp.org or Online Submission Portal.
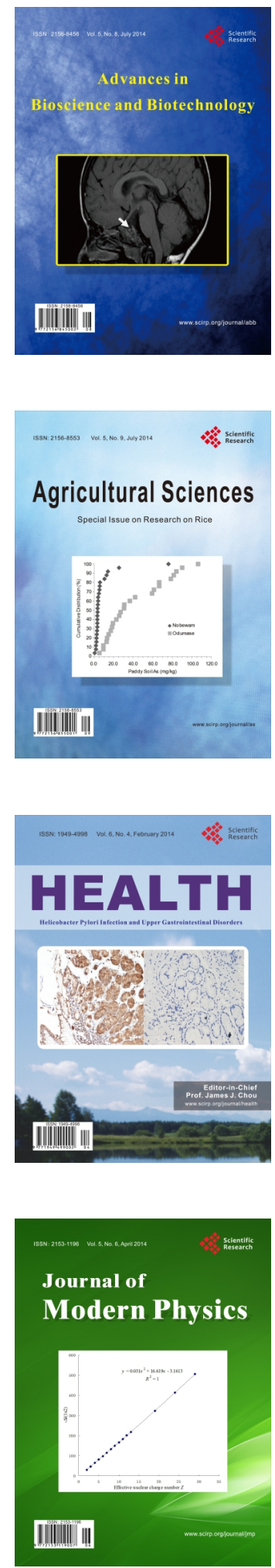
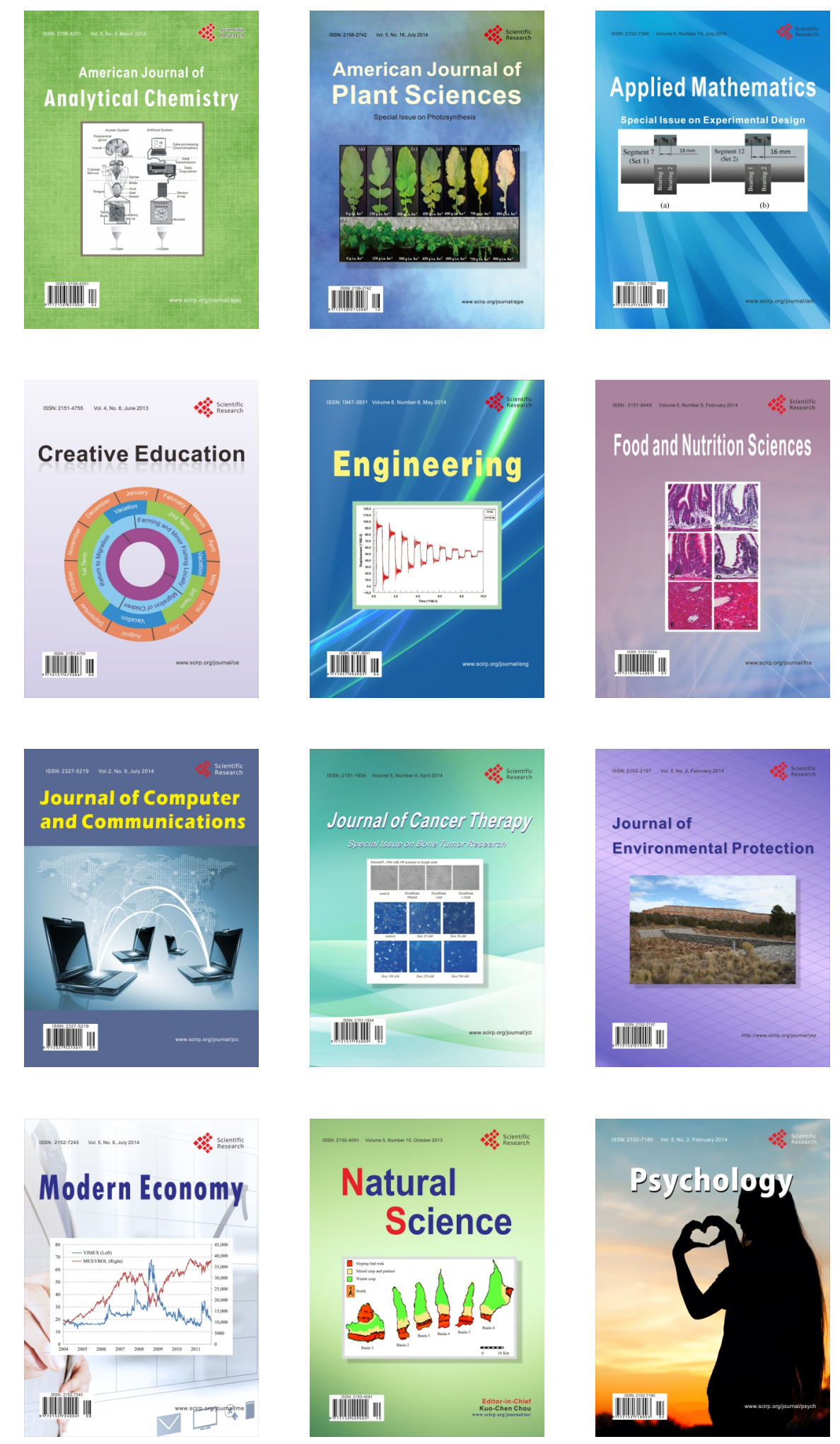